EVIDENCE BASED PUBLIC HEALTH POLICY AND PRACTICE

\title{
Community level risk factors for numbers of landmine victims in Chad and Thailand
}

\author{
L H Moulton, A A Benini
}

J Epidemiol Community Health 2003;57:956-959

See end of article for authors' affiliations .....................

Correspondence to: Dr L H Moulton, Department of International Health, Room E5519, 615 North Wolfe Street, Baltimore, MD 21205, USA:

Imoulton@ihsph.edu

Accepted for publication 19 May 2003

\begin{abstract}
Study objective: To determine commonalities of landmine victim risk factors in two very different countries. Design and setting: Data on 249 communities in Chad and 530 in Thailand were collected during 20002001 as part of the Global Landmine Survey. Community level variables were analysed in a series of Poisson mixture models with number of landmine victims as the dependent variable. Models developed for each country were tested on the other to investigate similarities and robustness of identification of risk factors.

Main results: Increased community level risk was associated with population size, closeness to another community with victims, emplacement in the previous two years, blocked water or pasture, and the proximity of unexploded ordnance or anti-tank mines. In Chad, risk factors tended to be more related to identifying communities that had crossed a threshold between near zero and moderate risk; Thailand, factors were more related to increases in victim rates.

Conclusions: Current systems of collecting data on community characteristics and landmine victims can provide meaningful risk factor information. Remediation approaches that focus on blockage of important resources and areas of recent, high intensity conflicts may be the most beneficial in reducing the numbers of victims.
\end{abstract}

other regions. Later conflicts between 1988 and 1994 added to the extensive UXO littering. Local informants estimated that contaminated areas cover a total land surface of up to 1081 square kilometres. ${ }^{8}$

Of the 530 mine affected communities in our Thailand data, over half are located along the Cambodian border, with the remaining split between the Burmese, Laotian, and Malaysian borders. In the Cambodian border region, mines were laid as recently as 1996, and near the border with Myanmar, mine laying was still active in 2002 in conflicts related to ethnic armed factions and to drug smuggling. The total contaminated area in Thailand was estimated to be 2557 square kilometres, ${ }^{9}$ much of it in large national forest tracts. During the 24 month periods covered in our analysis datasets, there were 339 persons killed or injured in Chad and 346 in Thailand as the result of landmine/ UXO incidents; the GLS identified thousands more earlier victims.

The focus here is on characteristics of communities that are associated with the existence and/or the increase of risk of injuries, many of which result in fatalities. The analytical design is to determine the best fitting regression models for each country separately, and then apply those models to the alternate country. This is similar to the use of a training dataset and validation dataset for construction and evaluation of medical diagnostic or prognostic models, except that the data from the two countries are treated symmetrically. Each dataset serves in turn as both a training and a validation set. Variables that are found to be associated with landmine victim rates in both of the two validation models may be more likely to be useful in the identification of other hazardous areas in the world.

Abbreviations: UXO, unexploded ordnance; GLS, Global Landmine Survey 


\section{METHODS}

\section{Survey organisation and data collection}

Data were collected as part of the activities of Level One Impact Surveys carried out under the aegis of the GLS. The GLS is funded by the United Nations, donor governments, and non-governmental organisations, and its survey activities are coordinated by the Survey Action Center, which until 2001 was located within the Vietnam Veterans of America Foundation. The goal of these surveys is to assess the human and socioeconomic impact of mines and UXO in a uniform manner in the world's most affected countries. We use data from two of the three earliest country surveys: (1) data collected in Chad on a subcontract to Handicap International-France, from September 2000 to March 2001, and (2) data collected in Thailand on a subcontract to Norwegian People's Aid, from November 2000 to January 2001. Survey teams use a variety of data sources, from official records to local informants, to gather information at the community level on landmine victims, resources with access blocked by landmines, and general community characteristics.

Of the data collected routinely as part of these two surveys, we examined all community level variables that were common to the surveys, including: total population, existence of primary or secondary schools, health centres, and fuel availability, whether there were anti-personnel or anti-tank mines or UXO, distance to the nearest community with victims, whether landmines were emplaced in the previous two years, and blockage of housing, water, pasture, and main or other roads.

\section{Statistical analysis}

Our analytical approach was to fit regression models relating community level characteristics to the occurrence of landmine injuries or deaths. More specifically, the response variable was the number of persons in a community who had become victims during the 24 month period before the survey. This was regressed on the explanatory variables via zero inflated Poisson models (ZIP). ${ }^{10}$ The software package Stata (7.0) was used (Stata Corportation, TX, 2001). This model form was chosen based on the count nature of the data and inspection of the victim distributions (fig l) that clearly indicated an "excess" number, with respect to standard count models, of communities with zero victims. The existence of two distributions is posited: one for the communities whose victim numbers follow a Poisson distribution; one for the communities with effectively zero risk of victims. We refer to these as increased risk and minimal risk communities, respectively. The results of fitting the corresponding mixture model are two sets of covariate vectors. The first is from a logistic regression specification that examines the odds of being in the Poisson distribution (increased risk communities) compared with the point distribution at zero (minimal risk communities). The second, from the Poisson regression model, estimates incidence rates for those observations generated by the Poisson component of the model.

For each country, we began by screening the variables with a backwards stepwise process that required a p value of 0.2 or less for a variable to remain in an ordinal logistic regression model for the number of victims, and 0.1 or less to re-enter. For each country, all variables that remained in this model were then entered in both components of a ZIP regression model. The next step was to refit the ZIP model taking out all terms with an associated $p$ value greater than 0.2 ; then, to make successive fits eliminating each term with the highest $p$ value greater than 0.2 ; then successively eliminating those with $\mathrm{p}$ values greater than 0.1 . We did not eliminate variables down to the more common level of 0.05 because we wanted

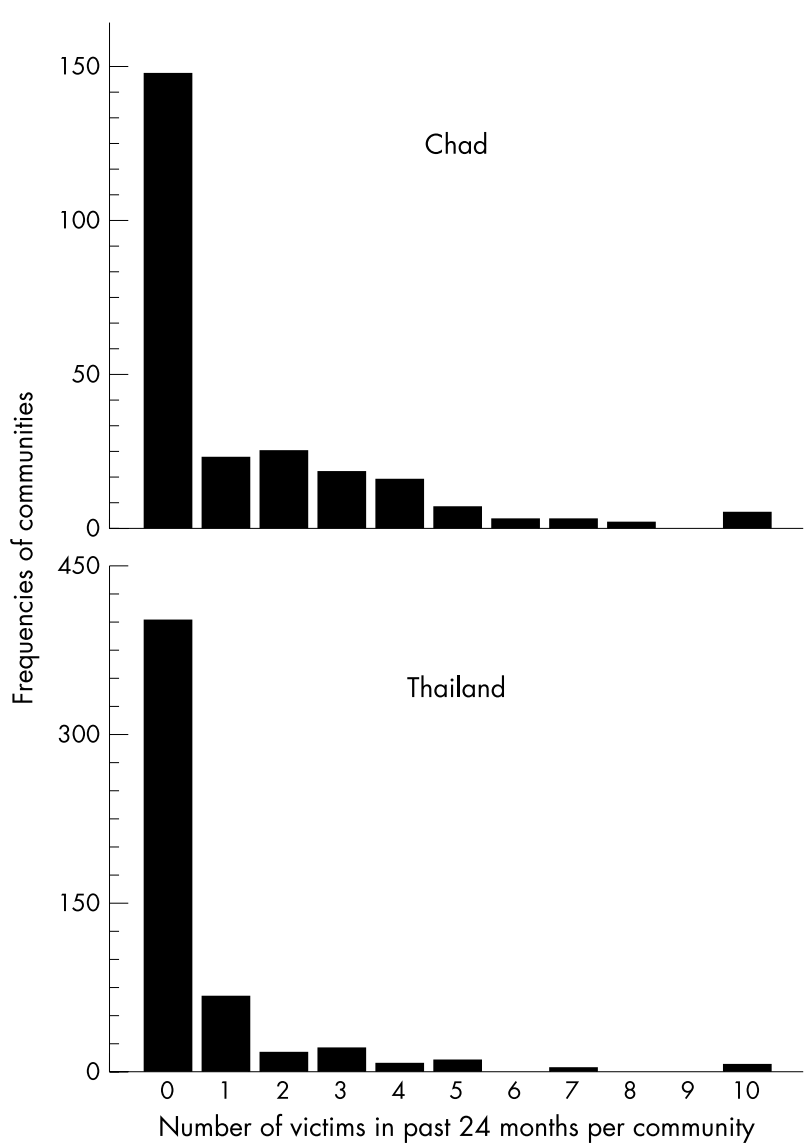

Figure 1 Distributions of numbers of victims per community in the two years before the 2000-2001 surveys in Chad and Thailand.

greater opportunity for a variable that might not be quite statistically significant in one formulation to appear as such in another. The remaining models are referred to as the "best" models for each country. We then fit each of these specifications to the other country's data to see how robust the models were across these two countries. With two places each variable could be in a model, there were a large number of potential models, and limited data, so that although the best models for each country might look somewhat different, we wanted to assess their plausibility in the other countries' contexts.

\section{RESULTS}

We had victim data for 249 communities in Chad, and 530 communities in Thailand. The distributions of the numbers of victims per community in each country are displayed in figure 1. In Chad, 147 (59\%) of the communities did not have any victims in the two year period, which was the case for $399(75 \%)$ of the communities in Thailand. The spread of the non-zero numbers of victims was large in both countries. Characteristics of the variables that were important in the stepwise modelling are given in table 1 . The variables for schools, health centres, fuel availability, and housing blockage did not remain in either of the models during the initial screening process at the $\mathrm{p}<0.1$ level. Full information on these variables for fitting the multivariate models was available for $222(89 \%)$ and $482(91 \%)$ of the communities in Chad and Thailand, respectively.

The four sets of model results are in table 2. Population size, distance to the nearest community with victims, emplacement in the previous two years, and blocked pasture and water figured prominently in both of the best stepwise 
Table 1 Descriptive data for the community level explanatory variables among surveyed communities in Chad and Thailand, 2000-2001

\begin{tabular}{|c|c|c|}
\hline Variable & Chad ( $n=222)$ & Thailand $(n=482)$ \\
\hline Median population (5th and 95th centiles) & $500(100,5000)$ & $582(170,1820)$ \\
\hline $\begin{array}{l}\text { Distance }(\mathrm{km}) \text { to nearest community with } \\
\text { victims ( } 5 \text { th and } 95 \text { th centiles) }\end{array}$ & $24(1.7,127)$ & $7(0.7,214)$ \\
\hline Mine/UXO* emplacement in previous two years & $11(5 \%)$ & $44(9 \%)$ \\
\hline Pasture blockage by mines/UXO & $11(50 \%)$ & $128(29 \%)$ \\
\hline Road blockage by mines/UXO & $83(37 \%)$ & $19(4 \%)$ \\
\hline Water source blockage by mines/UXO & $45(20 \%)$ & $135(28 \%)$ \\
\hline Anti-personnel mines reported & $50(23 \%)$ & $414(86 \%)$ \\
\hline UXO reported & $193(87 \%)$ & $341(71 \%)$ \\
\hline Anti-tank mines reported & $74(33 \%)$ & $148(31 \%)$ \\
\hline
\end{tabular}

*Unexploded ordnance (UXO) refers to explosive devices such as grenades or bombs that have been deployed but have not yet exploded because of malfunction or design.

models (these are the "training" models, referred to as Best Chad and Best Thai). In the Best Chad model, the variables tended to be most important in the logistic model component that distinguishes between the minimal risk and increased risk communities, whereas in the Best Thai model, more variables were in the component that determines how high the rates go for the increased risk communities. Existence of anti-personnel mines and UXO was significant for Chad, while anti-tank mines were significant for Thailand. In Thailand, blocked water sources were associated with greater risk. In Chad, however, although having blocked water indicated higher risk among those already in the increased risk communities, it was associated with a lower chance of being in that set of communities. This seems to be attributable to partial interaction with the rest of the variables: as they are removed from the model one by one, the coefficient for blocked water becomes less negative, and then positive (that is, odds ratio $>1$ for being in the increased risk group).

The "validation" models consist of taking each country's best model and applying it to the other country's data. We fit the Best Chad model specification to the Thailand data, and found many of the variables to be significant. Population size, distance to the nearest community with victims, emplacement in the previous two years, blocked water, and having UXO were all important. Alternatively, applying the Best Thai specification to the data from Chad, there was a similar picture: population size, distance to the nearest community with victims, emplacement in the previous two years, blocked pasture, and having anti-tank mines all remained statistically significant.

As an example in interpreting the odds ratios and rate ratios, consider the Best Thai results. A 10-fold increase in population size was associated with a $42 \%$ (95\% CI: $-6 \%$ to $114 \%$ ) increase in the incidence rate among the increased risk communities, and with more than double $(2.42 ; 95 \%$ CI: 1.00 to 5.36) the odds of being in that set of communities. A 10fold increase in the distance to the nearest community with victims reduced the odds of being in the increased risk group by $(1-0.29) \times 100 \%=71 \%$; or, equivalently, increased the odds of being in the minimal risk group by more than threefold $(1 / 0.29=3.4)$. The odds of being in the increased risk group goes up by a factor of 2.97 for communities with emplacement of explosives in the previous two years, and once in that group, the incidence rate is increased by a factor of 1.87 if there was such recent emplacement.

\section{DISCUSSION}

Although attention is often focused on characteristics of the landmine victim, such as age and occupation, we have performed analyses at the level of the community. Landmine

Table 2 Zero inflated Poisson models for landmine victim counts in the two years before the 2000-2001 surveys in Chad and Thailand, as functions of community level variables

\begin{tabular}{|c|c|c|c|c|c|c|c|c|}
\hline \multirow{2}{*}{$\begin{array}{l}\text { Community level explanatory variables } \\
\text { in each model component } \\
\text { Poisson component for rate in } \\
\text { increased risk group }\end{array}$} & \multicolumn{2}{|c|}{$\begin{array}{l}\text { Best Chad } \\
\text { Model* }^{*}\end{array}$} & \multicolumn{2}{|c|}{$\begin{array}{l}\text { Best Chad Model fit } \\
\text { to Thai data }\end{array}$} & \multicolumn{2}{|c|}{ Best Thai Model } & \multicolumn{2}{|c|}{$\begin{array}{l}\text { Best Thai Model fit } \\
\text { to Chad data }\end{array}$} \\
\hline & $\operatorname{Exp}(b) \dagger$ & $95 \% \mathrm{Cl} \ddagger$ & $\operatorname{Exp}(b)$ & $95 \% \mathrm{Cl}$ & $\operatorname{Exp}(b)$ & $95 \% \mathrm{Cl}$ & $\operatorname{Exp}(b)$ & $95 \% \mathrm{Cl}$ \\
\hline $\log _{10}($ Population) & 1.25 & 0.99 to 1.58 & 1.53 & 1.02 to 2.29 & 1.42 & 0.94 to 2.14 & 1.33 & 1.04 to 1.71 \\
\hline Mine/UXO emplacement in previous two years & & & & & 1.87 & 1.33 to 2.64 & 1.35 & 0.90 to 2.04 \\
\hline Pasture blockage by mines/UXO & & & & & 1.42 & 1.07 to 1.90 & 1.48 & 1.04 to 2.10 \\
\hline Water source blockage by mines/UXO & 1.37 & 1.05 to 1.80 & 1.37 & 1.01 to 1.86 & & & & \\
\hline $\begin{array}{l}\text { Unexploded ordnance reported } \\
\text { Logistic component for odds of } \\
\text { being in increased risk group }\end{array}$ & 2.05 & 0.88 to 4.76 & 0.61 & 0.44 to 0.85 & & & & \\
\hline $\log _{10}$ (Population) & 3.87 & 1.62 to 9.25 & $2.32 \S$ & 1.00 to 5.36 & 2.32 & 1.00 to 5.36 & 1.76 & 0.91 to 3.43 \\
\hline $\begin{array}{l}\log _{10}(\text { Distance }(\mathrm{km}) \text { to nearest } \\
\text { community with victims) }\end{array}$ & 0.25 & 0.13 to 0.51 & 0.24 & 0.14 to 0.40 & 0.29 & 0.17 to 0.48 & 0.19 & $0.10,0.36$ \\
\hline Mine/UXO emplacement in previous two years & 14.6 & 1.14 to 188 & 4.28 & 1.78 to 10.3 & 2.97 & $1.32,6.70$ & 6.72 & 1.07 to 42.2 \\
\hline Pasture blockage by mines/UXO & 7.44 & 2.91 to 19.0 & 1.63 & 0.91 to 2.90 & & & & \\
\hline Water source blockage by mines/UXO & 0.26 & 0.07 to 0.92 & 1.39 & 0.77 to 2.52 & 1.88 & 1.06 to 3.35 & 0.63 & 0.25 to 1.58 \\
\hline Road blockage by mines/UXO & 7.28 & 2.21 to 24.0 & 1.30 & 0.35 to 4.88 & & & & \\
\hline Anti-personnel mines reported & 9.04 & 1.93 to 42.3 & 1.32 & 0.50 to 3.54 & & & & \\
\hline Unexploded ordnance reported & 31.4 & 3.72 to 265 & 2.48 & 1.29 to 4.78 & & & & \\
\hline Anti-tank mines reported & & & & & 2.72 & 1.52 to 4.85 & 3.07 & 1.46 to 6.45 \\
\hline
\end{tabular}

*"Best" refers to final model in a backwards stepwise variable selection process using the Chad data; the next set of columns results from analysis of the same variables with the Thailand data. The last two sets of columns reverse the roles of the two countries' data. †Exponentiated coefficients yield rate ratios in the Poisson component, odds ratios in the binomial logistic component. $\$ 95 \%$ Confidence intervals for the exponentiated coefficient. §The entries for this variable are only coincidentally equal to those for the Best Thai Model; they differ in the fourth significant digits. 
decontamination efforts are organised at community level, and having indicators as to which communities may be at greatest risk of future victims can aid in prioritising this work.

We found several community characteristics to be associated with victim risk, regardless of country and model component specification. Perhaps most consistent in its association was distance to the nearest community with victims, a variable that captures the spatial correlation inherent to conflicts and mining operations. Population size was also highly consistent in its association with victim risk. In ordinary Poisson regression models, it is assumed that the count of victims will be proportional to the person years of exposure. Our results indicate the relation to be less than proportional, with rates going up only $20 \%-50 \%$ as population sizes increase 10-fold. Even the odds of being in the Poisson, non-zero risk group only doubled or quadrupled. It may be that larger communities do not have many more persons engaged in activities, agricultural or otherwise, that bring them in contact with landmines, with increased opportunity for alternative employment. After all, there is only so much land near any community that can be owned and/or worked.

Having had landmines/UXO emplaced in the two years before the survey was associated with increased risk. In areas of comparatively recent conflict, the populace may not yet have had sufficient experience or accumulated knowledge as to the precise location and extent of minefields. We have reported previously on factors related to communities' abilities to adapt to landmines over time, which include pressure on resources and institutional endowments. ${ }^{7}$ The laying of anti-tank mines, and UXO, both indicative of high intensity conflicts, were important factors in both countries. Blockage of water and pasture was a problem in both Chad and Thailand (as it was for roads in Chad), indicating high priority for clearance of mined areas in proximity to such resources.

The principal limitation of this study is that it draws on data collected by two separate subcontractors, with possible slight differences in data acquisition methods. For example, there seem to be different levels of accuracy in the reported distance measures. The probable direction of any bias would be to reduce the possibility of finding commonalities in relations across the two countries, not of invalidating those that have been identified. An important goal of the GLS is to provide consistent data across all of the surveyed countries, and there is a high degree of standardisation and quality control checking that goes into the acquisition and management of the data. None the less, the data were not collected expressly for the purpose of facilitating the present analyses.

The data collection efforts in Chad and Thailand were among the first to be performed as part of the GLS. They were chosen because of a combination of perceived urgency of the situations, the political stability and accessibility of the countries, and the speed of advance assessment teams. As further surveys are conducted, it will be of interest to see to what extent the variables in our analyses continue to be implicated. We expect the results of our analyses to be most applicable to those countries that have had recent and intense conflicts. For areas where the conflicts are more distal in time, the communities may have made more extensive adaptations, perhaps through marking off contaminated

\section{Key points}

- Blockage of resources, including water and pasturage, and recent emplacement of mines were associated with greatly increased rates of landmine incidents that claimed human victims in both Chad and Thailand.

- Depending on the country, factors have differential associations with being in a non-zero risk community, and with having higher victim rates.

- Large scale landmine impact surveys can also provide useful risk factor information.

areas, or through development of alternative sources of water and access to land. Such efforts would tend to diminish the importance of the corresponding variables.

As the consequences, both for individuals and communities, of the use of landmines in conflicts throughout the world are better understood, organisations involved in remediating these legacies will be better equipped to perform their task. The current efforts of the GLS may be expected to result in a variety of products that can both increase awareness on the part of donors of the extent of problems faced by communities, and facilitate the process of safeguarding these communities through successful mine awareness, fencing off mined areas, and clearance activities. Our results can give some general guidance that can be adapted to specific situations; further analyses of the type we have presented can help refine the prioritisation process for remediation of affected areas.

\section{Authors' affiliations}

L H Moulton, Departments of International Health and Biostatistics, Johns Hopkins Bloomberg School of Public Health, Baltimore, USA

A A Benini, Global Landmine Survey, Washington, DC, USA

The Survey Action Center and its partners in the Global Landmine Survey are not responsible for the views expressed in this article.

\section{REFERENCES}

1 Human Rights Watch. Landmine monitor report 2001. New York: Human Rights Watch, 2001.

2 Ascherio A, Biellik R, Epstein A, et al. Deaths and injuries caused by land mines in Mozambique. Lancet 1995;346:721-4.

3 Meade P, Mirocha J. Civilian landmine injuries in Sri Lanka. J Trauma 2000;48:735-9.

4 Newman RD, Mercer MA. Environmental health consequences of land mines. Int J Occup Environ Health 2000;6:243-8.

5 Andersson N, da Sousa CP, Paredes S. Social cost of land mines in four countries: Afghanistan, Bosnia, Cambodia, and Mozambique. BMJ 1995; 16:718-21

6 Krug EG, Ikeda RM, Qualls ML, et al. Preventing land mine-related injury and disability: a public health perspective. JAMA 1998;280:465-6.

7 Benini AA, Moulton LH, Conley CE. Landmines and local community adaptation. Journal of Contingencies and Crisis Management 2002;10:82-94.

8 Survey Action Center and Handicap International. Landmine impact survey: Republic of Chad. Washington, DC: Survey Action Center and Handicap International, 2002.

9 Survey Action Center and Norwegian's People's Aid. Landmine impact survey: Kingdom of Thailand. Washington, DC: Survey Action Center and Norwegian People's Aid, 2003.

10 Lambert D. Zero-inflated Poisson regression, with an application to defects in manufacturing. Technometrics 1992;34:1-14. 